\title{
Treadmill Training Improves Intravenous Glucose Tolerance and Insulin Sensitivity in Fatty Zucker Rats
}

\author{
K. Becker-Zimmermann, M. Berger, P. Berchtold, F.A. Gries, L. Herberg and M. Schwenen \\ Diabetes Research Institute, Departments of Medicine E and Physiological Chemistry II, \\ University of Düsseldorf, FRG
}

\begin{abstract}
Summary. The effect of treadmill training on intravenous glucose tolerance and insulin sensitivity was investigated in Zucker rats $(f a f a)$. In 25 -week-old fafa animals with the typical metabolic syndrome of massive obesity, glucose intolerance, hypertriglyceridaemia and insulin resistance, treadmill exercise of only very mild intensity was carried out for 6 weeks. The training programme induced a marked reduction in basal and post-glucose challenge plasma insulin levels and a slight but significant improvement of intravenous glucose tolerance. No alteration in insulin sensitivity of the isolated perfused hindquarter was demonstrable. In another study a 9-week training programme was started in 7-week-old fafa rats before the development of their metabolic syndrome. In the sedentary control animals glucose intolerance and insulin resistance developed during the study period; in the training group, both the deterioration of glucose tolerance and the decrease of insulin sensitivity were prevented. This study demonstrates in fafa rats that (a) in young animals physical training may prevent a genetically predisposed deterioration of glucose tolerance and insulin sensitivity and (b) in adult animals mild physical training may improve intravenous glucose tolerance and insulin sensitivity.
\end{abstract}

Key words: Physical training, obesity, diabetes, hypertriglyceridaemia, glucose intolerance, Zucker rat, insulin resistance, perfused hindquarter.

The therapeutic possibility of substantially improving impaired glucose tolerance by physical training in man has often been claimed, but has not been convincingly proven [1-4]. We have recently demonstrated an improvement of IV glucose tolerance by physical training programmes in normal rats [5]. Furthermore, it has been shown that basal and post-glucose insulinaemia decrease in normal rats with physical training [5-8]. In association with this obvious improvement in whole-body insulin sensitivity, an increase in insulin sensitivity of skeletal muscle glucose metabolism was demonstrated $[5,6]$.

In the present study, we have investigated the metabolic effects of physical training in fatty Zucker rats, a syndrome of genetic obesity which resembles Type 2 (non-insulin-dependent) diabetes mellitus. These rodents develop insulin resistance, hyperinsulinaemia, glucose intolerance, hyperlipoproteinaemia and adiposity $[9,10]$. The results indicate that development of glucose intolerance in these animals may be prevented by a physical training programme if initiated relatively early in life.

\section{Materials and Methods}

\section{Materials}

Bovine serum albumin (Cohn fraction V, Miles Laboratories, Slough, UK) was dissolved in Krebs-Henseleit buffer and dialysed twice against bicarbonate saline solution [11] for $24 \mathrm{~h}$.

$\mathrm{L}-\left[1-{ }^{14} \mathrm{C}\right]$-lactate was obtained from New England Nuclear Chemicals, Dreieichenhain, FRG. All enzymes for metabolic assays were purchased from Boehringer Mannheim, FRG and all substrates for experiments from Merck, Darmstadt, FRG. Crystalline bovine insulin was obtained from Hoechst, Frankfurt (Main), FRG. Phadebas insulin test (solid phase radioimmunoassay) was procured from Deutsche Pharmacia, Produktgruppe Diagnostika, Frankfurt (Main), FRG [5].

\section{Animals}

Two groups of animals were investigated: Group A, female obese Zucker rats, aged approximately 25 weeks and weighing $570 \mathrm{~g}$; and group B, female obese Zucker rats, aged 7 weeks and weighing $190 \mathrm{~g}$. All animals were bred in the animal laboratories of the Dia- 
betes Research Institute, Düsseldorf, FRG [10]. The animals were kept in individual cages with free access to food (normal Purina Chow pellets) and water during the entire study. Body weight and food intake were measured daily.

\section{Treadmill Training}

Groups A and B were divided into training and weight-matched control subgroups, ie. within each group there was a training subgroup and a sedentary subgroup. Training consisted of running in a motor-driven circular treadmill, with a speed of approximately $12 \mathrm{~m} / \mathrm{min}$. Group A was trained for 6 weeks beginning with $10 \mathrm{~min}$ on the first day up to $30 \mathrm{~min}$ daily during the last 4 weeks of the training programme. It was impossible to train the 25 -week-old Zucker rats for longer than $30 \mathrm{~min} /$ day because of their immobility due to excessive adiposity. For group B initial training was $10 \mathrm{~min}$ on the first day up to two periods of $120 \mathrm{~min}$ daily in the last week of the 9 weeks' training programme. During the entire training period the rats ran approximately $12 \mathrm{~km}$ (group A) and $61 \mathrm{~km}$ (group B) respectively.

\section{Experiments in Vivo}

Eight days before and $48 \mathrm{~h}$ after the experimental periods glucose tolerance tests were performed at $9.00 \mathrm{~h}$ in fed animals anaesthetized with pentobarbital ( $40 \mathrm{mg} / \mathrm{kg}$ body weight, IP) [5]. For the glucose tolerance test, D-glucose $(1 \mathrm{~g} / \mathrm{kg}$ body weight) in a $25 \%(\mathrm{w} / \mathrm{v})$ solution was injected into the femoral vein after surgical exposure. Wounds were closed with silk sutures. Immediately before and 5 , 20 and 60 min after the glucose injection, blood samples were collected from the tip of the tail for later determination of blood glucose concentrations and plasma insulin levels.

In additional studies group A (6 weeks trained) and group B ( 9 weeks trained), as well as their sedentary controls, were anaesthetized with pentobarbital $48 \mathrm{~h}$ after the last running exercise for dissection of the gastrocnemius muscle. These tissue samples were rapidly frozen and stored in liquid $\mathrm{N}_{2}$ for determination of citrate synthase activity and lipid extraction. Thereafter the animals were killed and the carcasses frozen for measurement of body composition. Parallel to these experiments, trained and untrained animals of both groups were anaesthetized in the same way and then subjected to hindquarter perfusion. Blood samples for measurement of serum triglycerides and serum cholesterol were taken by puncture of the inferior vena cava during preparation for the hindquarter perfusion [10].

\section{Perfusion Procedure}

Details of the perfusion apparatus, the operative preparation of the hindquarter and the composition of the perfusate were described previously [11-14]. The operative procedure differed slightly in that here the skin of both hindlimbs was only partially removed to allow freeze-clamping of the muscle at the end of each experiment. After placement in the perfusion apparatus, the hindquarter was perfused cyclically with $150 \mathrm{ml}$ of standard medium ( $\mathrm{pH} 7.4)$, which contained glucose $(5.5 \mathrm{mmol} / \mathrm{l})$, bovine albumin $(4 \mathrm{~g} / 100 \mathrm{ml})$, lactate $(1.5-2 \mathrm{mmol} / 1)$, pyruvate $(0.15 \mathrm{mmol} / \mathrm{l}), 5 \mu \mathrm{Ci}$ of $\mathrm{L}-\left[1-{ }^{14} \mathrm{C}-\right] \mathrm{lac}-$ tate, and aged washed human erythrocytes $(7 \mathrm{~g}$ haemoglobin/ $100 \mathrm{ml})$. In the experiments insulin $(1.0 \mathrm{mU} / \mathrm{ml})$ was added to the perfusate. The flow rate through the preparation $(11 \mathrm{ml} / \mathrm{min})$ was monitored with a Gilmont flow meter (A.S. Thomas, Philadelphia, $\mathrm{Pa}$, USA). Throughout the perfusion, the pressure in the tubing leading to the aortic catheter was $8.0-9.5 \mathrm{kPa}(60-70 \mathrm{mmHg})$. Perfusion was carried out for 10 min to allow for equilibration; thereafter baseline samples were collected. The hindquarter was then perfused for $30 \mathrm{~min}$.
Duplicate samples of the perfusate were taken at 0 and $30 \mathrm{~min}$; glucose uptake and release rates of lactate were calculated from the changes in perfusate concentration and expressed in $\mu \mathrm{mol} / 30 \mathrm{~g}$ muscle $\times \min [11]$. At the end of the perfusion period, a sample of the perfused muscle was freeze clamped and stored in liquid $\mathrm{N}_{2}$ for later measurement of tissue metabolites and lactate specific radioactivity. Lactate oxidation was determined from the amount of ${ }^{14} \mathrm{CO}_{2}$ produced by the hindquarter and the lactate-specific radioactivity in the perfused muscle, according to Berger et al. [13]. The $\mathrm{O}_{2}$ content of the whole perfusate was determined in arterial and venous samples at the mid-point of the perfusion period by using a LEX $-\mathrm{O}_{2}-\mathrm{CON}$ analyser (Lexington Instruments, Lexington, $\mathrm{Ma}$, USA) [14].

\section{Analytical Methods}

Tissue specimens were powdered under liquid $\mathrm{N}_{2}$ in a Mikro-Dismembrator (Braun, Melsungen, FRG). Perfusate and powdered tissue were deproteinized in ice cold $\mathrm{KClO}_{4} 10 \%(\mathrm{w} / \mathrm{v})$; precipitate was removed by centrifugation at $3000 \mathrm{~g}$ for $10 \mathrm{~min}$. Body composition analyses were performed as described previously $[5,10]$.

The triglyceride concentration of the gastrocnemius muscle was assayed by fat extraction with chloroform-methanol (Folch-extraction, modified). After evaporation of all chloroform-methanol, extracted triglycerides were resuspended in $5 \%$ Tween 80 -chloroform. The chloroform was again evaporated and the remaining triglycerides-Tween 80 -suspension was dissolved in $0.9 \% \mathrm{NaCl}$-solution before measurement.

After homogenisation of deep-frozen isolated gastrocnemius muscle and ultrasonication of the homogenates [14], the activity of citrate synthase (E.C.4.1.3.7.) was measured at $30^{\circ} \mathrm{C}$ as described by Srere [16].

Glucose and lactate concentrations in perchloric acid extracts were then measured spectrophotometrically using standard enzymatic assays as described previously [11,12]. Plasma glucose and plasma insulin levels, serum cholesterol and triglycerides in serum and muscle extracts were measured as described previously $[5,10]$.

\section{Calculations}

For each animal the areas under blood glucose and plasma insulin time curves were determined by planimetry and expressed in arbitrary units. In these analyses, $5.0 \mathrm{mmol} / 1$ and $0.86 \mathrm{mmol} / 1$ were used as baseline concentrations for blood glucose and plasma insulin respectively.

\section{Statistical Methods}

All results are expressed as mean \pm SEM. Statistical significance was assessed by using Student's t-test; only when data obtained from the same animals at different time were compared was the paired t-test used.

\section{Results}

\section{Experiments in Vivo}

In 25-week-old fatty Zucker rats (group A), in which the full syndrome of obesity, insulin resistance, and hyperlipoproteinaemia was already present, treadmill training had no influence on body weight, daily food intake, serum cholesterol or serum triglycerides during the study (Table 1). 
Table1. Effects of treadmill training in fafa Zucker rats

\begin{tabular}{|c|c|c|c|c|c|c|c|c|}
\hline & \multirow{2}{*}{$\begin{array}{l}\text { Initial } \\
\text { body weight } \\
\text { (g) }\end{array}$} & \multirow{2}{*}{$\begin{array}{l}\text { Weight gain } \\
\text { during the } \\
\text { study } \\
\text { (g) }\end{array}$} & \multirow{2}{*}{$\begin{array}{l}\text { Daily food } \\
\text { intake } \\
\text { (g/day) }\end{array}$} & \multirow{2}{*}{$\begin{array}{l}\text { Proportion } \\
\text { of muscle in } \\
\text { hindquarter } \\
(\%)\end{array}$} & \multirow{2}{*}{$\begin{array}{l}\begin{array}{l}\text { Serum } \\
\text { cholesterol }\end{array} \\
(\mathrm{mmol} / \mathrm{l})^{\mathrm{a}}\end{array}$} & \multirow{2}{*}{ 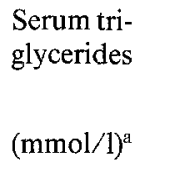 } & \multicolumn{2}{|c|}{ M. gastrocnemius ${ }^{\mathrm{a}}$} \\
\hline & & & & & & & \multicolumn{2}{|c|}{$\begin{array}{l}\text { Citrate Triglycerides } \\
\text { synthase }^{\mathrm{b}} \\
(\text { (nmol/g wet weight) }\end{array}$} \\
\hline \multicolumn{9}{|c|}{ Group A: 25 week-old fafa rats } \\
\hline $\begin{array}{l}\text { Control rats } \\
\quad(n=12)\end{array}$ & $569+11$ & $20 \pm 5$ & $23 \pm 0.4$ & $69 \pm 2(5)$ & $1.71 \pm 0.26$ & $11.45 \pm 2.13$ & - & - \\
\hline $\begin{array}{l}\text { Trained rats } \\
\qquad(n=16)\end{array}$ & $562 \pm 4$ & $18+5$ & $24 \pm 0.5$ & $71 \pm 3(6)$ & $1.55 \pm 0.18$ & $11.85 \pm 2.55$ & $22.1 \pm 2.0(5)$ & $795.3 \pm 163.1(6)$ \\
\hline \multicolumn{9}{|c|}{ Group B: 7 week-old $f a f a$ rats } \\
\hline $\begin{array}{l}\text { Control rats } \\
\quad(n=14)\end{array}$ & $178+10$ & $244+11$ & $24 \pm 0.4$ & $67 \pm 2(6)$ & $1.81 \pm 0.23$ & $18.47 \pm 0.76$ & $25.2 \pm 1.7(4)$ & $566 \pm 99$ \\
\hline $\begin{array}{l}\text { Trained rats } \\
\qquad(n=12)\end{array}$ & $183 \pm 8$ & $196 \pm 4^{c}$ & $23 \pm 0.6$ & $70 \pm 2(6)$ & $1.24 \pm 0.05^{c}$ & $7.41 \pm 1.21^{\mathrm{c}}$ & $22.3 \pm 0.7(5)$ & $297 \pm 69^{c}$ \\
\hline
\end{tabular}

Table 2. Effects of treadmill training on intravenous glucose tolerance in fafa rats: Area under the blood glucose and plasma insulin time curves

\begin{tabular}{|c|c|c|c|c|c|c|}
\hline & \multicolumn{3}{|c|}{ Area under blood glucose time curve } & \multicolumn{3}{|c|}{ Area under plasma insulin time curve } \\
\hline & First GTT & $p$ & Second GTT & First GTT & $p$ & Second GTT \\
\hline \multicolumn{7}{|c|}{ Group A: 25-week-old fafa rats } \\
\hline 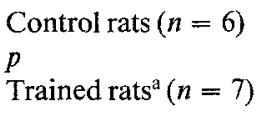 & $\begin{array}{l}0.39 \pm 0.06 \\
\text { NS } \\
0.32 \pm 0.01\end{array}$ & $\begin{array}{l}\text { NS } \\
\text { NS }\end{array}$ & $\begin{aligned} & 0.42 \pm 0.03 \\
< & 0.01 \\
& 0.32 \pm 0.03\end{aligned}$ & $\begin{array}{l}0.47 \pm 0.06 \\
\text { NS } \\
0.53 \pm 0.03\end{array}$ & $\begin{array}{l}<0.003 \\
<0.05\end{array}$ & $\begin{aligned} & 0.76 \pm 0.07 \\
< & 0.005 \\
& 0.45 \pm 0.06\end{aligned}$ \\
\hline \multicolumn{7}{|c|}{ Group B: 7-week-old fafa rats } \\
\hline $\begin{array}{l}\text { Control rats }(n=6) \\
p \\
\text { Trained } \text { rats }^{\mathrm{b}}(n=5)\end{array}$ & $\begin{array}{l}0.59 \pm 0.09 \\
\text { NS } \\
0.47 \pm 0.04\end{array}$ & $\begin{array}{l}<0.05 \\
\text { NS }\end{array}$ & $\begin{aligned} & 0.92 \pm 0.14 \\
< & 0.01 \\
& 0.49 \pm 0.03\end{aligned}$ & $\begin{array}{l}0.21 \pm 0.03 \\
\text { NS } \\
0.23 \pm 0.08\end{array}$ & $\begin{array}{l}\text { NS } \\
\text { NS }\end{array}$ & $\begin{array}{l}\quad 0.23 \pm 0.04 \\
\mathrm{NS} \\
\quad 0.32 \pm 0.07\end{array}$ \\
\hline
\end{tabular}

Results are expressed as mean $\pm \mathrm{SEM} ; p=$ difference between the two groups; NS $=$ not significant; ${ }^{\mathrm{a}}$ trained for 6 weeks, ${ }^{b}$ trained for 9 weeks

Glucose tolerance and plasma insulin levels were comparable in the two subgroups of group $\mathrm{A}$ at the start of the study (Table 2, Fig.1). At the end of the experimental period, there was a significant difference in glucose tolerance between the two groups (Table 2, Fig.1): training was associated with a smaller area under the plasma glucose time curve. On the other hand, the rise in plasma insulin following the glucose challenge increased in the controls, but decreased in the training group. Plasma insulin levels after glucose were lower in the training group than in the control animals (Table 2, Fig. 1).

Much more marked effects were seen in the 7week-old Zucker rats (group B), which had been trained for 9 weeks for up to two periods of $120 \mathrm{~min}$ daily. In the control animals the development of insulin resistance, which occurs spontaneously in this species, was observed during the experimental period.

Training resulted in a significantly smaller increase of body weight in trained than in control rats, while daily food intake was identical. This effect was associated with a significant decrease of serum cholesterol and triglycerides in the trained Zucker rats (Table 1). During the 9 week observation period, glucose tolerance deteriorated substantially in the control group (Fig. 2, Table 2). By contrast, in the training group, the glucose tolerance curve remained essentially unchanged (Fig. 2, Table 2), even though the ba- 

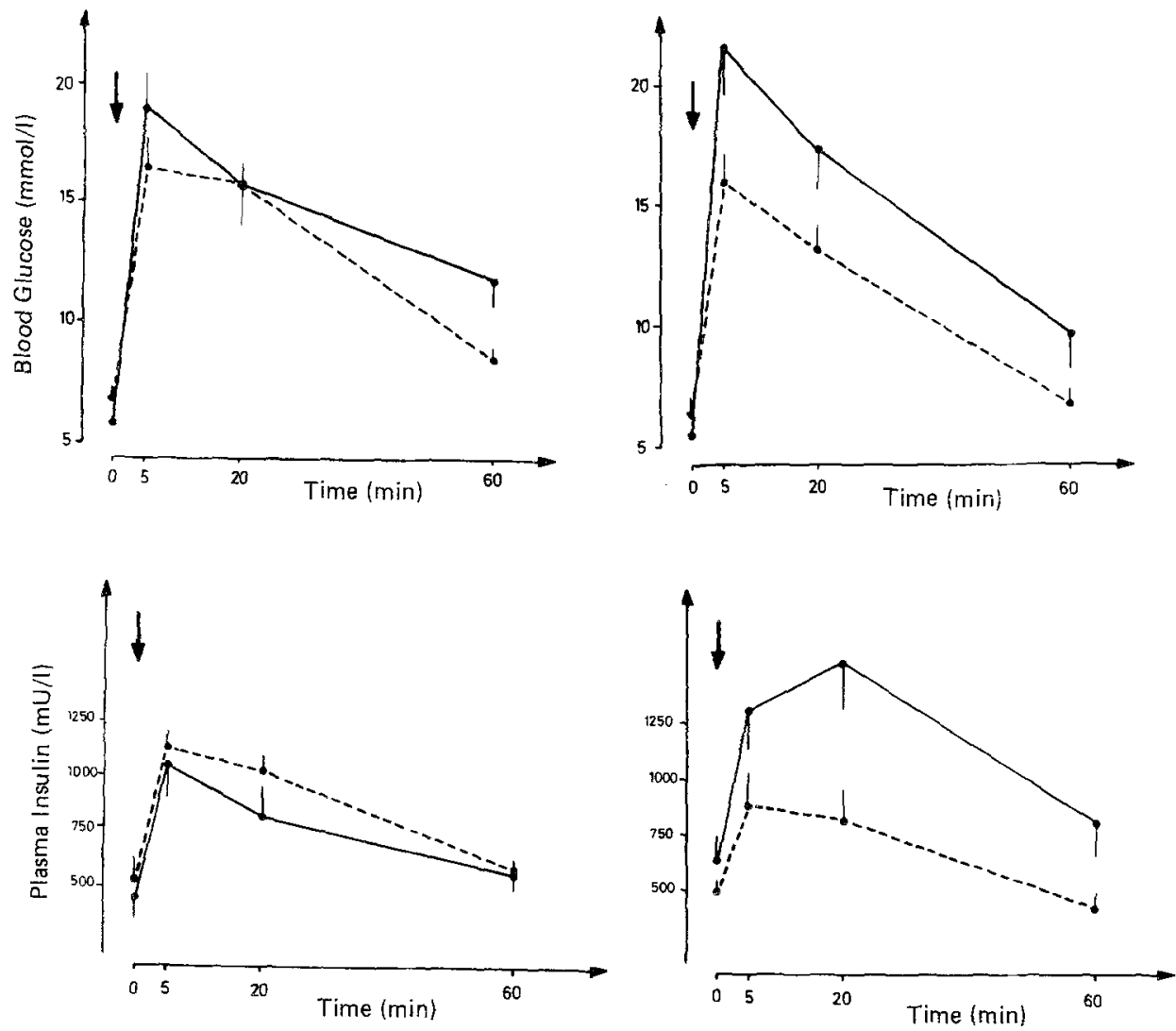

Fig. 1. Effect of treadmill training on intravenous glucose tolerance of Zucker rats ( $f a f a)$ (group A). The first glucose tolerance test was performed in 25 -week-old animals $(-1$ = control rats, $n=6 ;-\ldots=$ training group, $n=7)$; the second glucose tolerance test was performed following a 6-week training or control period. The arrows indicate the intravenous administration of $1 \mathrm{~g}$ glucose $/ \mathrm{kg}$ body weight. For statistical evaluation see Table 2

sal plasma glucose level was significantly lower after the training period $(p<0.05)$. As a result at the end of the study, glucose tolerance (as judged by the area under the glucose concentration time curve) was significantly better in the trained animals than in their sedentary controls (Fig. 2, Table 2). No difference between plasma insulin levels in the training and the control groups was observed either at the beginning or at the end of the study.

\section{Experiments in Vitro}

Body composition analysis: At the end of the 6-week and 9-week treadmill periods, the proportion of skeletal muscle in the lower half of the body was identical in trained and control Zucker rats, both in 25- and 7week-old animals (Table 1).

Citrate synthase activity: Citrate synthase activities in the gastrocnemius muscle remained unaffected by treadmill training (Table 1).
Lipid concentration in gastrocnemius muscle: In group B, training was associated with a significantly lower triglyceride content of the gastrocnemius muscle (Table 1). Unfortunately no comparison was carried out in group A. Even in the trained animals, however, triglyceride depots were substantially increased when compared with the younger rats $(p<0.05)$.

Perfused hindquarter: Insulin sensitivity of the skeletal muscle mass was determined using the isolated perfused rat hindquarter with an insulin concentration of $1.0 \mathrm{mU} / \mathrm{ml}$ in the medium, a concentration which had been shown previously to be submaximally effective in these animals [10]. Skeletal-muscle glucose-uptake was only slightly increased in the trained 25-week-old rats compared with their controls. Lactate release, lactate oxidation and oxygen uptake were unaffected (Fig. 3). In contrast, glucose uptake of the perfused hindquarter of the 9-week-trained younger Zucker rats (group B) was significantly im- 
FIRST GLUCOSE TOLERANCE TEST SECOND GLUCOSE TOLERANCE TEST
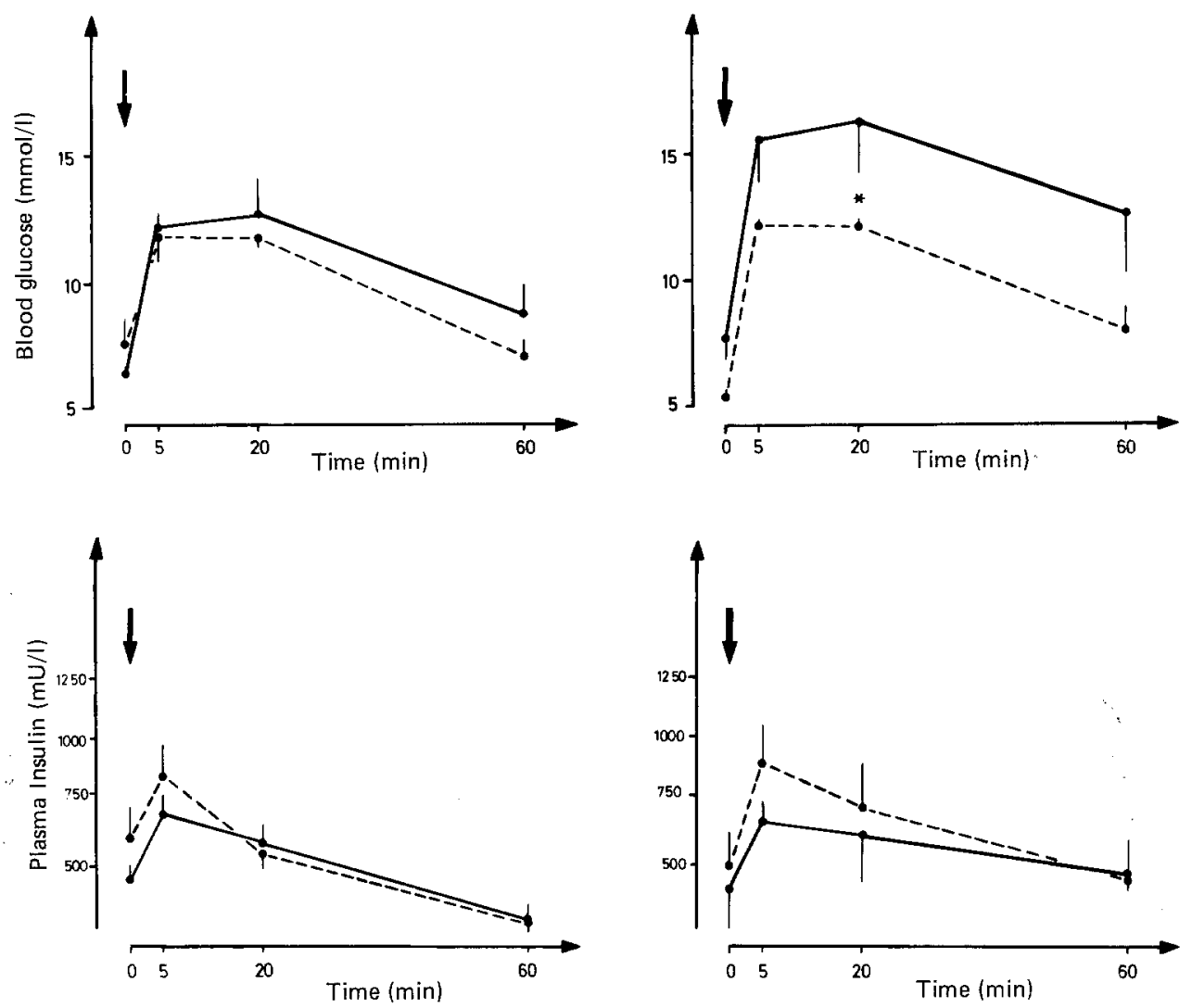

Fig. 2. Effect of treadmill training on intravenous glucose tolerance of Zucker rats ( $f a f a)$ (group B). The first glucose tolerance test was performed in 7-week-old animals ( - $=$ control rats, $n=6 ;---1$ = training group, $n=5$ ); the second glucose tolerance test was performed following a 9 -week training or control period. * = statistically significant difference for the two blood glucose concentrations between the trained and the control groups $(p<0.05)$

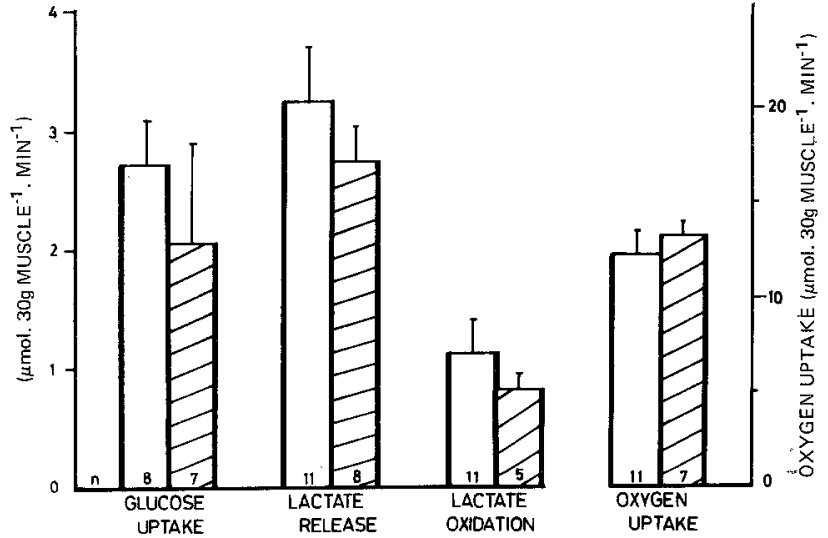

Fig. 3. Effect of 6 weeks treadmill training in 25-week-old Zucker rats (group A) on glucose uptake, lactate release, lactate oxidation

- and oxygen uptake of the isolated perfused rat hindquarter. $\square=$ trained rats; $=$ control rats. Results expressed as mean \pm SEM. In all experiments $1.0 \mathrm{mU}$ insulin $/ \mathrm{ml}$ were added to the perfusion medium

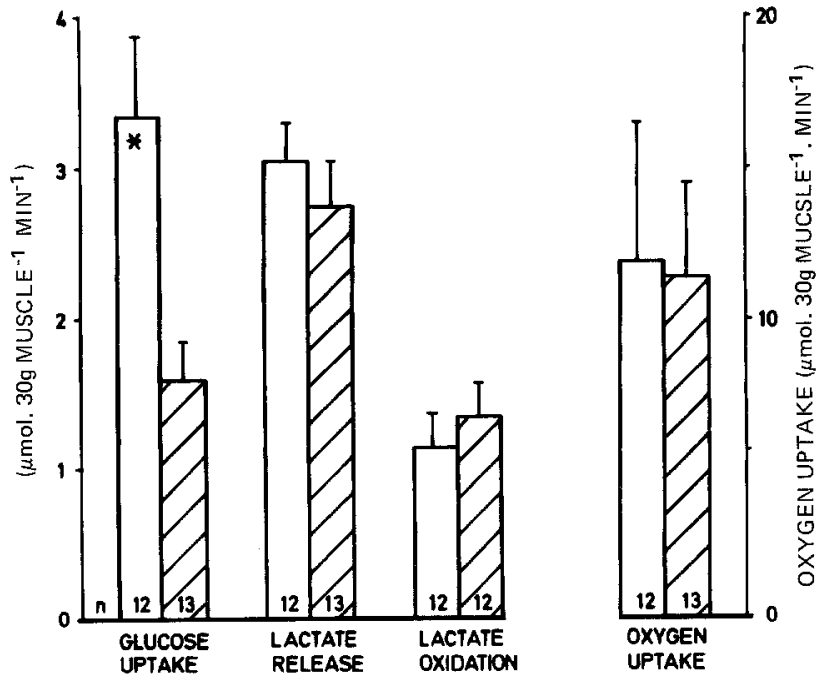

Fig. 4. Effect of 9 weeks treadmill training in 7-week-old Zucker rats (group B) on glucose uptake, lactate release, lactate oxidation and oxygen uptake of the isolated perfused rat hindquarter. $\square=$ trained rats; $\mathbb{Z}=$ control rats. Results expressed as mean \pm SEM. $*$ = statistically significant difference between the training and the control groups $(p<0.01)$. In all experiments $1.0 \mathrm{mU}$ insulin $/ \mathrm{ml}$ were added to the perfusion medium 
proved compared with their sedentary controls $(3.31$ \pm 0.52 versus $1.59 \pm 0.26 \mu \mathrm{mol} / 30 \mathrm{~g}$ muscle per min; $p<0.0025$; Fig. 4).

\section{Discussion}

Insulin insensitivity has been identified as a main cause of the impairment of glucose homeostasis in Type 2 diabetes mellitus. Thus, any rational attempt to treat this widespread disorder should include measures to improve the body's insulin sensitivity. In addition to hypocaloric diets and semi-starvation programmes, physical training should be helpful in restoring to normal peripheral responsiveness towards insulin. It has been demonstrated repeatedly in man and in animals that training is associated with an improvement of insulin sensitivity in vivo [1-5, 17-19] and of skeletal muscle preparations in vitro $[5,6]$. There is, however, very little evidence that physical training will, in fact, normalize glucose homeostasis in Type 2 diabetes or improve impaired glucose tolerance in man. In two studies in patients with maturity onset diabetes [20] or glucose intolerance [21] physical training induced only a minor improvement of glucose tolerance, or its effects were rather short-lived.

In normal rats, however, we have recently reported a substantial improvement of glucose tolerance and an associated increase of insulin sensitivity after physical training [5]. It is noteworthy that under usual maintenance conditions (restriction in small cages), small laboratory rodents lead quite a sedentary life and therefore the training might have normalized both the degree of habitual activity of this species and their glucose tolerance. (It is in keeping with this hypothesis that total immobilization of normal rats for three weeks does not induce a further deterioration of glucose tolerance [4].) Such a phenomenon has also been demonstrated in previously immobilized men, in whom glucose tolerance improves substantially when they resume their habitual physical activity $[1,3$, 22].

In this study we have investigated the effect of physical training on genetically obese rodents with glucose intolerance. In 25-week-old animals, which had already developed the full-blown metabolic syndrome (Table 1, Fig. 1), only a rather limited training programme could be carried out due to the enormous adiposity of these animals. During the 6 weeks of the study the increase in body weight was $<5 \%$ and was unaffected by the training programme. Likewise, serum cholesterol and triglyceride levels showed no difference between the control and training groups. There was, however, a definite effect on glucose tolerance: at the end of the training programme, the area under the plasma glucose time curve was significantly smaller in the training group, associated with a marked reduction in circulating insulin concentrations. However, the studies using the isolated perfused hindquarter in vitro did not reveal any significant increase in insulin sensitivity of skeletal muscle. In the younger group of fafa rats (group B) a more intense treadmill programme was carried out. Nevertheless, the animals more than doubled their body weight during the study period - but the treadmill trained animals gained significantly less weight, at an identical daily food intake. Training was also associated with significantly lower serum levels of cholesterol and triglycerides as has already been reported [23], and triglyceride content of the gastrocnemius muscle at the end of the study period (Fig. 1). As in our previous study in normal rats [5], the training was of mild intensity since both the tissue composition of the hindquarter and the citrate synthase activity of the gastrocnemius muscles remained unaffected (Table 1). In accordance with the natural history of the Zucker rat syndrome [9], control animals showed substantial deterioration of glucose tolerance during the observation period, i. e. between weeks 7 and 16 of their lives. This development of glucose intolerance was prevented in the training group, despite a doubling of body weight. As judged on the basis of circulating glucose and insulin levels (Fig. 2), initial insulin insensitivity deteriorated further in the control animals, whereas it was maintained in the training group. This is in keeping with the data from the isolated hindquarter experiments (Fig.4): insulin-stimulated glucose uptake was significantly higher in the trained than in the untrained animals.

These findings indicate that the deterioration of glucose tolerance in obese Zucker rats can be prevented by a physical training programme, perhaps due to relative preservation of insulin sensitivity during the phase of rapid weight gain in these animals. If the treadmill exercise is initiated in a later phase, i.e. beginning at week 25 when the faf $a$ rats have already developed their full metabolic syndrome, training programmes are much more difficult to carry out and less effective with respect to any improvement in insulin sensitivity, glucose tolerance or hypertriglyceridaemia.

As discussed previously [3-6], the possible mechanisms of this exercise-induced improvement of peripheral insulin sensitivity are still unknown. Exercise-induced facilitation of the insulin-receptor interaction $[24,25]$ and a causal role of repeated periods of tissue hypoxia $[26,27]$ during the training phase are still being discussed as possible mechanisms.

While definite studies in diabetic patients on the effect of exercise on glucose tolerance are still lacking 
this study proves for the first time that in young animals a genetically predisposed deterioration of glucose tolerance and insulin sensitivity may be prevented by physical training. Furthermore, in adult animals pre-existing glucose intolerance and insulin insensitivity can be ameliorated by mild physical training. This should further encourage attempts to evaluate the efficacy and practicability of physical training programmes in patients with Type 2 diabetes and in people who appear to be at a high risk of developing Type 2 diabetes.

Acknowledgements. This work has been supported by the Deutsche Forschungsgemeinschaft, SFB 113, Diabetes Forschung, Düsseldorf (grants G 2 Berger and C 1, C 2, Herberg). We thank Dr. F.W. Kemmer for reviewing the manuscript. The expert technical assistence of Ms. Schäfer, Major, Thiemann, Schnickmann and Ott is gratefully acknowledged.

\section{References}

1. Vranic M, Berger M (1979) Exercise and diabetes mellitus. Diabetes 28: 147-167

2. Berger M, Berchtold P, Kemmer FW (1980) Metabolic and hormonal effects of exercise in diabetic patients. In: Brownlee $M$ (ed) Handbook of Diabetes mellitus, vol III. Garland Press, New York, pp 273-306

3. Berger M, Berchtold P(1981) Physical training as a part of the therapy for adult onset diabetes. In: Björntorp $B$, Cairella $M$, Howard AN (eds) Recent advances of obesity research III. John Libbey, London, pp 341-347

4. Berger M, Becker-Zimmermann K, Herberg L (1982) Physical training in insulin resistant states. Int J Obes (in press)

5. Berger M, Kemmer FW, Becker K, Herberg L, Schwenen M, Gjinavcy A, Berchtold P (1979) Effects of physical training on glucose tolerance and on glucose metabolism of skeletal muscle in anaesthetized normal rats. Diabetologia 16:179-184

6. Mondon CE, Dolkas CB, Reaven CM (1980) Site of enhanced insulin sensitivity in exercise trained rats at rest. Am J Physiol 239:169-177

7. Richard D, LeBlanc $\mathbf{J}$ (1980) Effects of physical training and food restriction on insulin secretion and glucose tolerance in male and female rats. Am J Clin Nutr 33: 2588-2594

8. Galbo H, Richter EA, Holst JJ, Christensen NJ (1977) Diminished hormonal responses to exercise in trained rats. J Appl Physiol 43:953-958

9. Herberg L, Coleman D (1977) Laboratory animals exhibiting obesity and diabetes syndromes. Metabolism 26:59-99

10. Kemmer FW, Berger M, Herberg L, Gries FA, Wirdeyer A, Becker K (1979) Glucose metabolism in perfused skeletal muscle. Demonstration of insulin resistance in the obese Zucker rat. Biochem J 178: 733-741

11. Rudermann NB, Houghton CRS, Hems R (1971) Evaluation of the isolated perfused rat hindquarter for the study of muscle metabolism. Biochem J 124: 639-651

12. Berger M, Hagg SA, Rudermann NB (1975) Glucose metabo- lism in perfused skeletal muscle. Interaction of insulin and exercise on glucose uptake. Biochem J 146: 231-238

13. Berger M, Hagg SA, Goodman MN, Rudermann NB (1976) Glucose metabolism in perfused skeletal muscle. Effects of starvation, diabetes, fatty acids, acetoacetate, insulin and exercise on glucose uptake and disposition. Biochem J 158: 191-202

14. Kemmer FW, Berger M, Herberg L, Gries FA (1977) Effects of metformin on glucose metabolism of isolated perfused rat skeletal muscle. Drug Res 27:1573-1576

15. Baldwin KM, Klinkerfuss GH, Terjung RL, Mole PA, Holloszy JO (1972) Respiratory capacity of white, red and intermediate muscle: Adaptive response to exercise. Am J Physiol 222: 373-378

16. Srere PA (1969) Citrate synthase. Methods Enzymol 13:3-5

17. Björntorp $P(1975)$ Effects of physical conditioning in obesity. In: Bray GA (ed) Obesity in perspective, DHEW-Publication (NIH) 75: 708. Bethesda, USA, pp 397-406

18. Johansen K, Munck O (1979) The relationship between maximal oxygen uptake and glucose tolerance/insulin response ration in normal young man. Horm Metab Res 11:424-427

19. Cüppers HJ, Erdmann R, Schubert H, Berchtold P, Berger M (1982) Glucose tolerance, serum insulin and serum lipids in athlets. In: Berger M, Christacopoulos P, Wahren J (eds) Proceedings of the International Symposium 'Diabetes and Exercise'. Hans Huber, Bern, pp 155-165

20. Rudermann NB, Ganda OP, Johansen K (1979) The effect of physical training on glucose tolerance and plasma lipids in maturity onset diabetes. Diabetes 28 (Suppl): 89-92

21. Saltin B, Lindgärde F, Lithell $H$, Eriksson KF, Gad P (1980) Metabolic effects of long term physical training in maturity onset diabetes. In: Waldhäusl K (ed) Diabetes 1979, Exerpta Medica, Amsterdam, pp 345-350

22. Dolkas CB, Greenleaf JE (1977) Insulin and glucose responses during bed rest with isotonic and isometric exercise. J Appl Physiol 43: 1033-1038

23. Simonelli C, Eaton RP (1978) Reduced triglyceride secretion: a metabolic consequence of chronic exercise. Am J Physiol 234: E221-E227

24. LeBlanc J, Nadeau A, Boulay M, Rousseau-Migneron S (1979) Effects of physical training and adiposity on glucose metabolism and ${ }^{125} \mathrm{I}$-insulin binding. J Appl Physiol 46: 253-239

25. Pedersen O, Beck-Nielsen H, Heding L (1980) Increased insulin receptors after exercise in patients with insulin dependent diabetes mellitus. N Engl J Med 302: 886-892

26. Holm JSE (1972) Skeletal muscle metabolism in patients with peripheral arterial insufficiency. MD Thesis, University of Gotenburg

27. Hammarsten J (1980) Metabolic and morphological adaptation in patients with peripheral arterial insufficiency. MD Thesis, University of Gotenburg

Received: 21 July 1981

and in revised form: 1 February 1982

Professor Dr. Michael Berger

Medizinische Klinik E

Universität Düsseldorf

Moorenstr.5

D-4000 Düsseldorf, FRG 